Check for updates

Cite this: RSC Adv., 2019, 9, 30736

Received 22nd August 2019

Accepted 20th September 2019

DOI: $10.1039 / c 9 r a 06594 f$

rsc.li/rsc-advances

\section{5-Bromo-norborn-2-en-7-one derivatives as a carbon monoxide source for palladium catalyzed carbonylation reactions $\uparrow$}

\author{
China M. Payne, (D) Kyulee Cho and David S. Larsen (DD * \\ Norbornenone (5b), obtained from the reaction of 2,5-dimethyl-3,4-diphenylcyclopentadienone dimer (3) \\ with bromomaleic anhydride (4b), provides an excellent base-triggered source of carbon monoxide for \\ palladium-catalysed carbonylation reactions. Aminocarbonylation, ketoamide synthesis, and Suzuki- \\ Miyaura reactions of aryl iodides carried out in a two-chamber reaction vessel gave good to excellent \\ yields of carbonylated products.
}

\section{Introduction}

In order to avoid the use of carbon monoxide (CO) gas as a reactant in small scale reactions in situ generation from many sources including carbon dioxide, ${ }^{1}$ aldehydes, ${ }^{2}$ formates, ${ }^{3}$ and formamides $^{4,5}$ such as $\mathrm{N}$-formylsaccharin developed by Manabe and coworkers $^{6}$ has been utilized. This circumvents the need for equipping small-scale chemical laboratories with cylinders of this highly toxic, odourless and colourless gas. In early work, the most commonly used CO sources were metal carbonyl compounds such as $\mathrm{Mo}(\mathrm{CO})_{6}$ which proved useful, among others, for palladium catalysed aminocarbonylations and carbonylative Stille reactions of aryl halides. ${ }^{7-9}$ Recently, we have reported the development of norborneneone derivatives such as oCOm-21 as physiologically relevant carbon monoxide releasing molecules. This water soluble Carbon Monoxide Releasing Molecule (CORM) undergoes an E1 $1_{\mathrm{cB}}$ elimination of $\mathrm{HBr}$ to a norbornadienone intermediate that spontaneously undergoes cheletropic release of CO in TRISsucrose buffer at $\mathrm{pH} 7.4$ at $37{ }^{\circ} \mathrm{C}$ with a half-life of 19 minutes (Scheme 1). ${ }^{10}$ The rate of release is $\mathrm{pH}$ dependent and at higher $\mathrm{pH}$ the half-life is much reduced.

In parallel work to the development of these compounds, we viewed that simpler norborneneone constructs could provide readily accessible and bench stable $\mathrm{CO}$ sources for various palladium catalyzed carbonylation reactions as originally described by Heck, ${ }^{11}$ Suzuki and coworkers ${ }^{12}$ and Yamamoto. ${ }^{13}$ These would be an alternative to compounds such as silacarboxylic acids 1a-c and 9-methyl-fluorene-9-carbonyl chloride (2) for CO generation for use in two-chamber reaction system such as that developed, and comprehensively studied, by the Skrydstrup group. They have demonstrated the utility of this

Department of Chemistry, University of Otago, P.O. Box 56, Dunedin, 9054, New Zealand. E-mail: david.larsen@otago.ac.nz

$\dagger$ Electronic supplementary information (ESI) available: Experimental protocols, ${ }^{1} \mathrm{H}$ and ${ }^{13} \mathrm{C}$ NMR spectra. See DOI: $10.1039 / \mathrm{c} 9 \mathrm{ra06594f}$ approach, using SilaCOgen 1b and COgen 2 (along with their ${ }^{13} \mathrm{C}$ and ${ }^{14} \mathrm{C}$ labelled counterparts $)^{14}$ in a number of palladium catalysed carbonylations including, aminocarbonylation, ${ }^{15,16}$ double carbonylations, ${ }^{16}$ Heck, ${ }^{17,18}$ and Suzuki-Miyaura reactions of both aryl iodides and bromides. ${ }^{19-21} \mathrm{CO}$ release from COgen 2 is triggered in one chamber upon heating with a tritert-butylphosphine ligated palladium catalyst while that of silacarboxylic acids such as $\mathbf{1 a}$ produces $\mathrm{CO}$ at ambient temperature upon treatment with a fluoride source. The synthesis of both COgen (2) and SilaCOgen (1a) requires carboxylation with $\mathrm{CO}_{2}$ to install the carbonyl group (Fig. 1). More recently, this group have developed a tablet form of 2 that contains tri-tert-butylphosphonium tetrafluoroborate and $\mathrm{Pd}(\mathrm{OAc})_{2}$ which allows convenient CO generation without the need for use of a glovebox for carbonylative transformations. ${ }^{22}$

Herein, we report the development of readily accessible, stable norbornenone derivatives as efficient base-triggered CO donors as alternatives to $\mathbf{1}$ and $\mathbf{2}$ for palladium catalysed carbonylation reactions of aryl iodides using a twochamber reaction system without the need for glovebox equipment.

\section{Results and discussion}

Our initial investigations into the viability of norborneneone based CORMs as suitable CO donors for various palladium catalysed carbonylation utilized $\mathbf{5 a}$ as an ex situ CO surrogate.

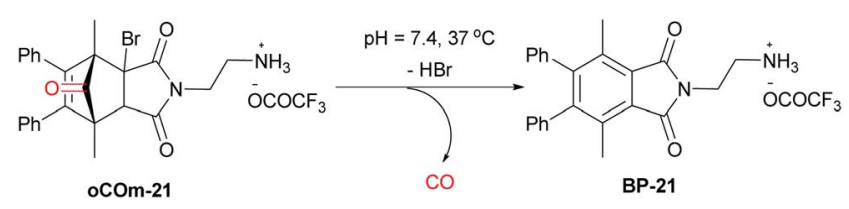

Scheme 1 oCOm-21, a physiologically relevant $\mathrm{CO}$ source. ${ }^{10}$ 


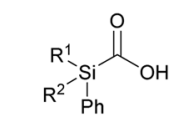

a. $\mathrm{R} 1=\mathrm{R} 2=\mathrm{CH}_{3}$

b. $\mathrm{R} 1=\mathrm{CH}_{3}, \mathrm{R} 2=\mathrm{Ph}$

c. $\mathrm{R} 1=\mathrm{tBu}, \mathrm{R} 2=\mathrm{Ph}$

1a-c

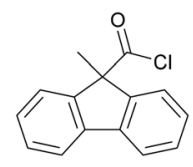

Cogen
Fig. 1 CO donor molecules developed by the Skrydstrup group.

2,5-Dimethyl-3,4-diphenylcyclopentadienone (3), readily available from the condensation of benzil and 3-pentanone, ${ }^{23}$ exists as a reversible dimer, which reacted smoothly with $\mathrm{N}$-phenyl-3bromomaleimide (4a) to give cycloadduct $\mathbf{5 a}$ in $71 \%$ yield as a bench stable solid (Scheme 2). The efficiency of $\mathbf{5 a}$ as a CO donor was tested with the aminocarbonylation of $p$-iodoanisole (6a) and butylamine (7), catalysed by $\mathrm{Pd}_{2}(\mathrm{dba})_{3}$ and using triethylamine as a base. This reaction gave $N$-butyl $p$-methoxybenzamide (8a) in $97 \%$ yield using a two-chamber reaction system similar to that developed by Skrydstrup et al. ${ }^{\mathbf{2 4}}$

Given the success of this reaction, the more readily accessible norbornadienone derivative $\mathbf{5 b}$ was synthesized from commercially available bromomaleic anhydride (4b) and cyclopentadienone dimer 3 as an 8:1 mixture of the endo and exoisomers in $96 \%$ yield, again as a bench stable solid. It was viewed that the anhydride moiety of $\mathbf{5 b}$ would better facilitate the base induced elimination of $\mathrm{HBr}$ due to the electron withdrawing property of the anhydride compared to that of imide 5a.

With the synthesis of cycloadduct $\mathbf{5 b}$ complete, we investigated the scope of this compound as a CO source for palladium-catalysed carbonylation reactions. Initially, aminocarbonylations using a range of aryl iodides as the limiting reagent with both butylamine and morpholine as coupling partners were investigated (Scheme 3). In general, 1.5 equivalents of $\mathrm{CO}$ donor $\mathbf{5 b}$ were dissolved in 1,4-dioxane and 2.0 equivalents of base were used to liberate CO in Chamber A. In all cases, complete conversion of $\mathbf{5 b}$ into $\mathbf{9}$ was observed. Furthermore, in Chamber B high conversions of aryl iodide substrates into amides $\mathbf{8 a - e}$ and 10a-e were observed with isolated yields after column chromatography ranging from 72 $99 \%$, as detailed in Tables 1 and 2 .

In addition to cycloadduct $\mathbf{5 b}$, a second $\mathrm{CO}$ source was investigated which produces a norbornadienone intermediate that spontaneously undergoes chelotropic loss of CO. A DielsAlder reaction was carried out between cyclopentadienone
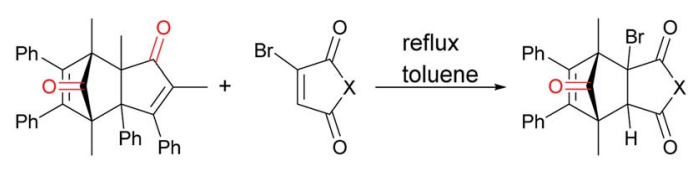

3

$5 \mathbf{a} X=\mathrm{NPh}$ 5b $X=0$

Scheme 2 Reaction of 3 and $4 a$ or $4 b$ to give corresponding cycloadduct 5 a or $5 b$.

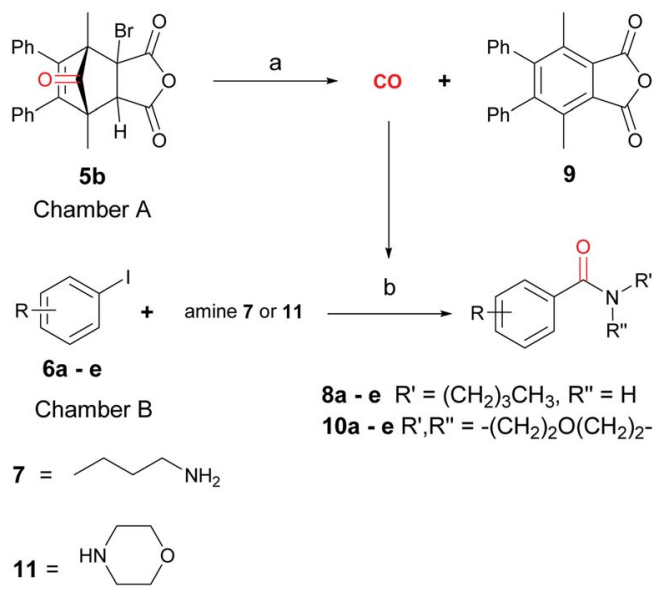

Scheme 3 General reaction scheme using $5 \mathrm{~b}$ as the $\mathrm{CO}$ source for aminocarbonylation reactions of aryl iodides $6 a-e$ and either $n$ butylamine (7) and morpholine (11) in 1,4-dioxane. Reagents and conditions: 80 or $100{ }^{\circ} \mathrm{C}, 20-25$ h. (A) $\mathrm{Et}_{3} \mathrm{~N}$ (1.5 eq.), 1,4-dioxane. (B) $\mathrm{Pd}_{2}(\mathrm{dba})_{3}(5 \mathrm{~mol} \%), \mathrm{PPh}_{3}$ (10 mol\%), Et $\mathrm{N}$ (2.3 eq.) 1,4-dioxane.

dimer 3 and diethyl acetylenedicarboxylate in the CO producing chamber (Scheme 4). On heating both chambers in 1,4-dioxane substituted benzene 12 (ref. 25) was produced in Chamber A in $91 \%$ yield. The aminocarbonylation reaction in Chamber B (see Table 1; Entries 1 and 2, note c) gave $N$-butyl-4-iodo- and $N$ butyl-4-nitro-benzamides (8a and $\mathbf{8 b}$ ) in 95 and $82 \%$ yields, respectively.

Table 1 Palladium-catalysed aminocarbonylation reactions carried out with aryl iodides and $n$-butylamine. All reactions were carried out at $80^{\circ} \mathrm{C}$ for 20 hours in a sealed two-chamber apparatus

\begin{tabular}{|c|c|c|c|c|}
\hline Entry & Aryl iodide & Product & Conversion $^{a}(\%)$ & Yield $^{b}(\%$ \\
\hline 1 & $\mathbf{6 a}, \mathrm{R}=p-\mathrm{MeO}$ & & 100 & $88(95)^{c}$ \\
\hline 2 & $6 \mathbf{b}, \mathrm{R}=p-\mathrm{NO}_{2}$ & & 100 & $99(82)^{c}$ \\
\hline 3 & $6 \mathrm{c}, \mathrm{R}=p-\mathrm{Br}$ & & 100 & 81 \\
\hline 4 & 6d, $\mathrm{R}=\mathrm{H}$ & & 100 & 97 \\
\hline 5 & $6 \mathrm{e}^{d}$ & & 90 & 88 \\
\hline
\end{tabular}

${ }^{a}$ Measured from ${ }^{1} \mathrm{H}$ NMR spectra of the crude reaction mixture as compared to the limiting reactant. An example is provided in Fig. SI1 (ESI). ${ }^{b}$ Isolated yields after column chromatography. ${ }^{c}$ Yield in brackets have been obtained from reactions using the alternative source of $\mathrm{CO}$ in Chamber $\mathrm{A}$ as shown in Scheme $4 .{ }^{d} \mathbf{6 e}=1$ iodonaphthalene. 
Table 2 Palladium-catalysed aminocarbonylation reactions carried out with aryl iodides $6 \mathrm{a}-\mathrm{e}$ and morpholine (9). All reactions were carried out at $100^{\circ} \mathrm{C}$ for 20 hours in a sealed two-chamber apparatus

\begin{tabular}{|c|c|c|c|c|}
\hline Entry & Aryl iodide & Product & Conversion $^{a}(\%)$ & Yield $^{b}\left({ }^{0}\right.$ \\
\hline 1 & 6a, $\mathrm{R}=p-\mathrm{MeO}$ & & $100(80)$ & $75(39)^{c}$ \\
\hline 2 & $\mathbf{6 b}, \mathrm{R}=p-\mathrm{NO}_{2}$ & & 100 & 88 \\
\hline 3 & $\mathbf{6 c}, \mathrm{R}=p-\mathrm{Br}$ & & 100 & 99 \\
\hline 4 & 6d, $\mathrm{R}=\mathrm{H}$ & 10d & 100 & 72 \\
\hline 5 & $6 \mathbf{e}^{d}$ & $10 \mathrm{e}$ & 80 & 75 \\
\hline
\end{tabular}

${ }^{a}$ Measured from ${ }^{1} \mathrm{H}$ NMR spectra of the crude reaction mixture as compared to the limiting reactant. An example is provided in Fig. SI1 (ESI). ${ }^{b}$ Isolated yields after column chromatography. ${ }^{c}$ Reaction carried out at $80{ }^{\circ} \mathrm{C}$ for $20 \mathrm{~h} .{ }^{d} \mathbf{6 e}=1$-iodonaphthalene.

In order to show the scope of cycloadduct $\mathbf{5 b}$ as a CO donor, other palladium catalysed carbonylation reactions were investigated. Following a 2006 report by Kondo et al. on room temperature double carbonylations, ${ }^{26}$ the Skrydstrup group have successfully utilized both COgen and SilaCOgen as an ex situ CO sources for double carbonylation reactions. ${ }^{15,27}$ The reaction of iodoanisole (6a) and butylamine (7) with $\mathrm{CO}$ generated from three equivalents of $\mathbf{5 b}$ in Chamber $\mathrm{A}$ gave doubly carbonylated $\alpha$-ketoamide product 13 in $64 \%$ yield. This result demonstrated that cycloadduct $\mathbf{5 b}$ could liberate $\mathrm{CO}$ at room temperature (Scheme 5).

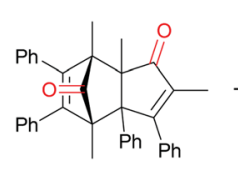

3
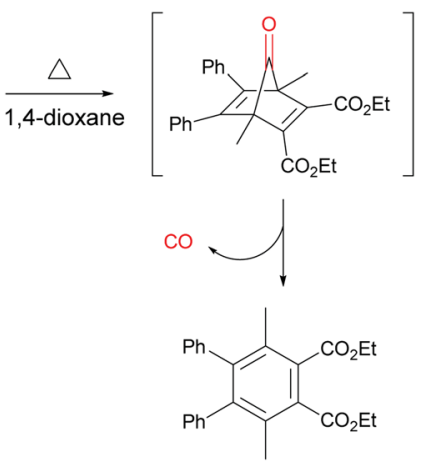

$12(91 \%)$
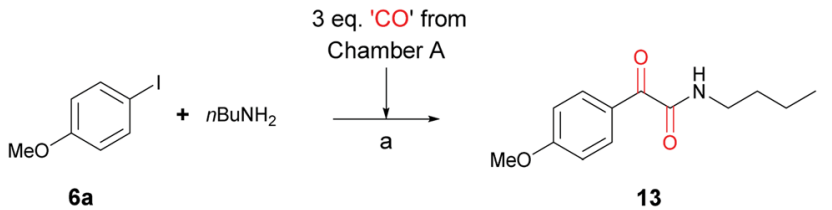

Scheme 5 The double carbonylation of $p$-iodoanisole (6a) and butylamine (7) using cycloadduct $5 \mathrm{~b}$ as a $\mathrm{CO}$ source. Chamber A: toluene, rt. (a) DBU (3.0 eq.), Chamber B: $\mathrm{Pd}_{2}(\mathrm{dba})_{2}(5 \mathrm{~mol} \%),\left[(t \mathrm{Bu})_{3} \mathrm{PH}\right]$ $\mathrm{BF}_{4}(10 \mathrm{~mol} \%), \mathrm{DBU}(2.0$ eq.), 64\%.

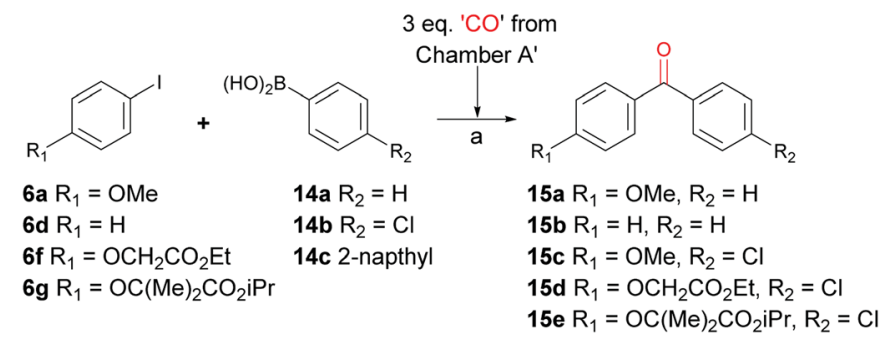

Scheme 6 Synthesis of aromatic ketones using $5 \mathrm{~b}$ (3.0 eq.) and $\mathrm{Et}_{3} \mathrm{~N}$ (3.5 eq.) in 1,4-dioxane as the $\mathrm{CO}$ source from Chamber A for palladium-catalysed carbonylative Suzuki-Miyaura reactions. Reagents and conditions: $80^{\circ} \mathrm{C}$; Chamber A: $5 \mathrm{~b}$ (3.0 eq.), NEt 3 (3.5 eq.), dioxane. Chamber B: aryl iodides 6 (1 eq.), $\mathrm{Pd}_{2}(\mathrm{dba})_{2}\left(2\right.$ mol\%), $\mathrm{K}_{2} \mathrm{CO}_{3}$ (3.0 eq.), anisole.

Another example of widely utilized palladium catalysed carbonylation reactions is the well-known Suzuki-Miyaura carbonylation. This was first reported in 1998 following development of the cross coupling reaction of the same name. ${ }^{28} \mathrm{~A}$ brief investigation into the optimization of reaction conditions for our system showed a ligand-free system could be used and a higher $\mathrm{CO} / \mathrm{Pd}^{(0)}$ ratio was necessary when compared to the aminocarbonylation reaction. This was achieved by using three equivalents of CO donor in the CO releasing chamber (Scheme 6). With optimized reaction conditions in hand, a series of Suzuki-Miyaura carbonylation reactions were carried out with the goal of synthesizing fenofibrate - a biologically relevant example of an unsymmetrical biaryl ketone. Entry 4, Table 3 shows the synthesis of a model system that involved the synthesis of simpler aryl iodide component $\mathbf{6 f}$ reacting with 4-chlorophenylboronic acid (14b) to give the corresponding biaryl ketone $\mathbf{1 5 d}$ in $75 \%$ yield. In a similar

Table 3 Suzuki-Miyaura carbonylation reactions carried out with selected aryl iodides and boronic acids. All reactions were carried out at $80{ }^{\circ} \mathrm{C}$ for 25 hours in a sealed two-chamber apparatus

\begin{tabular}{lllll}
\hline Entry $^{a}(\%)$ & Aryl iodide & Boronic acid & Product & Yield \\
\hline 1 & 6a & $\mathbf{1 4 a}$ & $\mathbf{1 5 a}$ & 74 \\
2 & 6d & $\mathbf{1 4 a}$ & $\mathbf{1 5 b}$ & 78 \\
3 & 6a & $\mathbf{1 4 b}$ & $\mathbf{1 5 c}$ & 94 \\
4 & $\mathbf{6 f}$ & $\mathbf{1 4 b}$ & $\mathbf{1 5 d}$ & 75 \\
5 & $\mathbf{6 g}$ & $\mathbf{1 4 b}$ & $\mathbf{1 5 e}$ & 80
\end{tabular}

Scheme 4 Reaction of 3 and diethyl acetylenedicarboxylate to give 12

${ }^{a}$ Isolated yields after column chromatography. and $\mathrm{CO}$. 


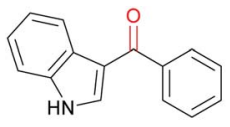

$17(50 \%)$

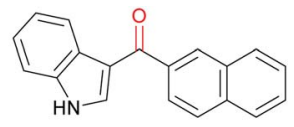

$18(44 \%)$

Fig. 2 3-Acyl indoles synthesised via Suzuki-Miyaura carbonylation reaction.
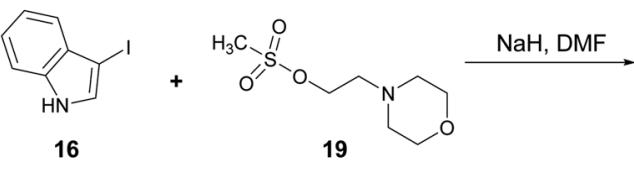

Scheme 7 Reaction of 3-iodo- $1 \mathrm{H}$-indole (16) with 2-morpholinoethyl methanesulfonate (20) to give iodoindole 21 . Reagents and conditions: DMF, NaH, 4 h, rt, 90\%.

manner iodide $\mathbf{6 g}$ and $\mathbf{1 4 b}$ gave fenofibrate $\mathbf{1 5 e}$ in an $80 \%$ yield (Entry 5, Table 3).

Recent literature has shown only a few examples of cannabimimetic indoles that have been synthesised via carbonylation reactions. ${ }^{29-31}$ The most relevant to this work involved a tandem $\mathrm{C}-\mathrm{H}$ bond iodination and carbonylative Suzuki-Miyaura crosscoupling. ${ }^{32}$ However, their process used gaseous CO and additives such as pyridine and CsF to facilitate the reaction. Trial carbonylation reactions of 3 -iodo- $1 H$-indole (16) with phenylboronic acid (14a) and 2-napthylboronic acid (14c) were carried out under the same conditions used for previous SuzukiMiyaura carbonylations to give 3-acyl indoles (17) and (18) in moderate yields (Fig. 2).

Synthetic acylindole cannabinoids are commonly functionalized at the indole nitrogen with an ethylmorpholine side chain. Early work into the structure activity relationships of synthetic cannabinoids found that this substituent had optimal binding activity at the $\mathrm{CB}_{1}$ receptor. ${ }^{33}$

$\mathrm{N}$-alkylation of 3 -iodo- $1 H$-indole (16) with mesylate 19 gave iodoindole 20 (Scheme 7) which was then subjected to SuzukiMiyaura carbonylation with 4-methoxyphenylboronic acid (14b) and 2-naphthylboronic acid (14c), respectively under the conditions described in Scheme 6. The corresponding acylindoles 21 and 22 were obtained in moderate yields (Fig. 3).
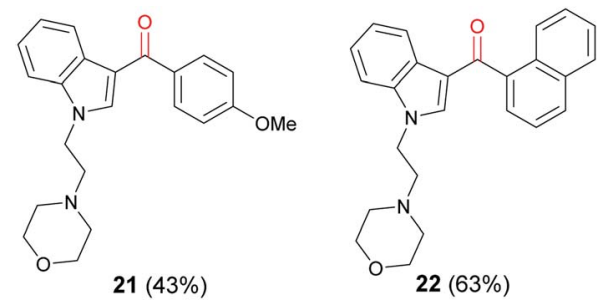

Fig. 3 Synthetic cannabinoid 3-acyl indoles synthesised via SuzukiMiyaura carbonylation reaction.

\section{Conclusions}

In conclusion, we have shown that readily synthesized norbornenones $\mathbf{5 a}$ and $\mathbf{5 b}$ are excellent alternatives to using $\mathbf{C O}$ gas for small scale carbonylation reactions using a two-chamber reaction system. CO release is triggered by organic bases such as triethylamine and DBU. With the latter base release is rapid even at room temperature which is essential for forming $\alpha$-ketoamides via a double carbonylation reaction. Alternatively, $\mathrm{CO}$ gas can be generated by the thermally promoted Diels-Alder reaction of cyclopentadienone $\mathbf{4}$ and diethyl acetylenedicarboxylate which was also effective for aminocarbonylation reactions.

\section{Experimental}

\section{Aminocarbonylation reactions}

General procedure A: synthesis of secondary amides from aryl halides and primary amine ( $n$-butylamine) using diethyl acetylenedicarboxylate as CO source. The two-chamber system, equipped with Teflon ${ }^{\circledR}$ coated magnetic stirrer bars, was loaded with all solid reagents. In Chamber A; diene dimer 3 (0.75 eq.). In Chamber $\mathrm{B} ; \mathrm{Pd}_{2}(\mathrm{dba})_{3}$ (0.025 eq.) and $\mathrm{PPh}_{3}$ (0.1 eq.). Then, all liquid reagents were added via syringe: to Chamber A: 1,4dioxane $(5 \mathrm{~mL})$ and diethyl acetylenedicarboxylate (1.5 eq.); to Chamber B: 1,4-dioxane ( $4 \mathrm{~mL}$ ), aryl halide 6 (1 eq.; aryl halides that were solids at room temperature were added with the catalyst and ligands), $n$-butylamine (7) (2.3 eq.) and $\mathrm{Et}_{3} \mathrm{~N}(2.3$ eq.). The system was sealed with screwcaps fitted with silicon seal inserts. The two chamber system was heated in an oil bath at $80{ }^{\circ} \mathrm{C}$ with stirring, for $20 \mathrm{~h}$. The reaction mixture was cooled to $\mathrm{rt}$ then the solvents in Chamber A and $\mathrm{B}$ were individually concentrated in vacuo. The crude material obtained was purified by silica gel column chromatography.

General procedure B: synthesis of secondary and tertiary amides from aryl halides and primary amine ( $n$-butylamine) using cycloadduct $6 \mathrm{~b}$ as the CO source. The two-chamber system, equipped with Teflon ${ }^{\circledR}$ coated magnetic stirrer bars, was loaded with all solid reagents. In Chamber A; cycloadduct 5b (1.5 eq.). In Chamber $\mathrm{B} ; \mathrm{Pd}_{2}(\mathrm{dba})_{3}\left(0.025\right.$ eq.) and $\mathrm{PPh}_{3}(0.1$ eq.), the aryl halide ( 1 eq.), if solid. Then, all liquid reagents were added to Chamber B via syringe: aryl halide 6 (1 eq.) (if liquid), $n$-butylamine (2.3 eq.) and 1,4-dioxane (Chamber A: 5 $\mathrm{mL}$, Chamber B: $4 \mathrm{~mL}$ ). The system was cooled in an ice bath (with sodium chloride) and flushed with argon. $\mathrm{Et}_{3} \mathrm{~N}$ (2.3 eq.) was added to Chamber B via syringe, and the cap (fitted with a silicon seal insert) screwed in place. $\mathrm{Et}_{3} \mathrm{~N}$ (2.3 eq.) was also added to Chamber A via syringe, and the system was sealed. The two chamber system was heated in an oil bath at either 80 or $100{ }^{\circ} \mathrm{C}$ with stirring, for $20 \mathrm{~h}$. The reaction mixture was to cooled to rt then the solvent in Chamber B was concentrated in vacuo. The crude material obtained was purified by silica gel column chromatography.

\section{Suzuki-Miyaura carbonylation}

General procedure C: synthesis of unsymmetrical biaryl ketones using cycloadduct $6 \mathrm{~b}$ as the $\mathrm{CO}$ source. The two- 
chamber system, equipped with Teflon ${ }^{\circledR}$ coated magnetic stirrer bars, was loaded with all solid reagents. In Chamber A; cycloadduct $5 \mathbf{b}$ (3 eq.). In Chamber $\mathrm{B} ; \mathrm{Pd}_{2}(\mathrm{dba})_{3}$ (0.025 eq.), $\mathrm{K}_{2} \mathrm{CO}_{3}$ (3 eq.), boronic acid 14 (1.5 eq.) and aryl halide 6 (1 eq.), if solid. Then, all liquid reagents were added to Chamber B via syringe: aryl halide (1 eq.) (if liquid), and anisole $(5 \mathrm{~mL})$. The system was cooled in an ice bath (with sodium chloride) and flushed with argon, and the cap (fitted with a silicon seal insert) screwed in place. 1,4-dioxane (5 mL) was added to Chamber A, via syringe followed by $\mathrm{Et}_{3} \mathrm{~N}$ (2.3 eq.) and the system was sealed. The two chamber system was heated in an oil bath at $80^{\circ} \mathrm{C}$ with stirring, for $20 \mathrm{~h}$. The reaction mixture was cooled to rt, and the solvent in Chamber B was concentrated in vacuo. The crude material obtained was purified by silica gel column chromatography.

\section{Conflicts of interest}

The authors declare that there is no conflict of interest regarding the publication of this paper.

\section{Acknowledgements}

CMP thanks the University of Otago for financial support for an MSc stipend and DSL, the Marsden Fund (UOO1728), for financial support.

\section{Notes and references}

1 P. H. Gehrtz, V. Hirschbeck and I. Fleischer, Chem. Commun., 2015, 51, 12574-12577.

2 T. Shibata, N. Toshida and K. Takagi, Org. Lett., 2002, 4, 1619-1621.

3 S. Ko, H. Han and S. Chang, Org. Lett., 2003, 5, 2687-2690. 4 Y. Wan, M. Alterman, M. Larhed and A. Hallberg, J. Comb. Chem., 2003, 5, 82-84.

5 Y. Wan, M. Alterman, M. Larhed and A. Hallberg, J. Org. Chem., 2002, 67, 6232-6235.

6 T. Ueda, H. Konishi and K. Manabe, Org. Lett., 2013, 15, 5370-5373.

7 N.-F. K. Kaiser, A. Hallberg and M. Larhed, J. Comb. Chem., 2002, 4, 109-111.

8 K. Yamazaki and Y. Kondo, J. Comb. Chem., 2004, 6, 121-125.

9 J. Lindh, A. Fardost, M. Almeida and P. Nilsson, Tetrahedron Lett., 2010, 51, 2470-2472.

10 J. T. B. Kueh, N. J. Stanley, R. J. Hewitt, L. M. Woods, L. Larsen, J. C. Harrison, D. Rennison, M. A. Brimble, I. A. Sammut and D. S. Larsen, Chem. Sci., 2017, 8, 54545459.
11 A. Schoenberg and R. F. Heck, J. Org. Chem., 1974, 39, 33273331.

12 N. Miyaura and A. Suzuki, Chem. Rev., 1995, 95, 2457-2483. 13 F. Ozawa, N. Kawasaki, D. Okamoto, T. Yamamoto and A. Yamamoto, Organometallics, 1987, 6, 1640-1651.

14 P. Nordeman, S. D. Friis, T. L. Andersen, H. Audrain, M. Larhed, T. Skrydstrup and G. Antoni, Chem. - Eur. J., 2015, 21, 17601-17604.

15 P. Hermange, A. T. Lindhardt, R. H. Taaning, K. Bjerglund, D. Lupp and T. Skrydstrup, J. Am. Chem. Soc., 2011, 133, 6061-6071.

16 D. U. Nielsen, K. Neumann, R. H. Taaning, A. T. Lindhardt, A. Modvig and T. Skrydstrup, J. Org. Chem., 2012, 77, 61556165.

17 T. M. Gøgsig, D. U. Nielsen, A. T. Lindhardt and T. Skrydstrup, Org. Lett., 2012, 14, 2536-2539.

18 P. Hermange, T. M. Gøgsig, A. T. Lindhardt, R. H. Taaning and T. Skrydstrup, Org. Lett., 2011, 13, 2444-2447.

19 A. Ahlburg, A. T. Lindhardt, R. H. Taaning, A. E. Modvig and T. Skrydstrup, J. Org. Chem., 2013, 78, 10310-10318.

20 K. M. Bjerglund, T. Skrydstrup and G. A. Molander, Org. Lett., 2014, 16, 1888-1891.

21 S. D. Friis, T. L. Andersen and T. Skrydstrup, Org. Lett., 2013, 15, 1378-1381.

22 H. Collin, W. Reis, D. U. Nielsen, A. T. Lindhardt, M. Valle, R. Freitas and T. Skrydstrup, Org. Lett., 2019, 21, 5775-5778.

23 T. L. Andrew, J. R. Cox and T. M. Swager, Org. Lett., 2010, 12, 5302-5305.

24 S. D. Friis, R. H. Taaning, A. T. Lindhardt and T. Skrydstrup, J. Am. Chem. Soc., 2011, 133, 18114-18117.

25 Y. Kuninobu, M. Nishi, A. Kawata, H. Takata, Y. Hanatani, Y. S. Salprima, A. Iwai and K. Takai, J. Org. Chem., 2010, 75, 334-341.

26 M. Iizuka and Y. Kondo, Chem. Commun., 2006, 1739-1741, DOI: 10.1039/B600632A.

27 S. R. Laursen, M. T. Jensen, A. T. Lindhardt, M. F. Jacobsen and T. Skrydstrup, Eur. J. Org. Chem., 2016, 2016, 1881-1885.

28 T. Ishiyama, H. Kizaki, T. Hayashi, A. Suzuki and N. Miyaura, J. Org. Chem., 1998, 63, 4726-4731.

29 H.-T. Zhang, L.-J. Gu, X.-Z. Huang, R. Wang, C. Jin and G.-P. Li, Chin. Chem. Lett., 2016, 27, 256-260.

30 Z. Wang, Z. Yin and X.-F. Wu, Org. Lett., 2017, 19, 4680-4683. 31 F. Zeng and H. Alper, Org. Lett., 2013, 15, 2034-2037.

32 M.-N. Zhao, L. Ran, M. Chen, Z.-H. Ren, Y.-Y. Wang and Z.-H. Guan, ACS Catal., 2015, 5, 1210-1213.

33 M. A. Eissenstat, M. R. Bell, T. E. D'Ambra, E. J. Alexander, S. J. Daum, J. H. Ackerman, M. D. Gruett, V. Kumar and K. G. Estep, J. Med. Chem., 1995, 38, 3094-3105. 